\title{
MED Parallel system powered by Concentrating Solar Power (CSP). Model and Case study: Trapani, Sicily
}

\author{
Sérgio Casimiro $^{1,2}$, João Cardoso ${ }^{1}$, Christos Ioakimidis ${ }^{2}$, J. Farinha Mendes ${ }^{1}$, \\ Carmelo Mineo $^{3}$, Andrea Cipollina ${ }^{4}$ \\ ${ }^{1}$ Laboratório Nacional de Energia e Geologia, Lisboa, Portugal. \\ ${ }^{2}$ MIT-Portugal Program, Sustainable Energy Systems, Lisboa, Portugal \\ ${ }^{3}$ Sicilacque, S.p.A., Palermo, Italy \\ ${ }^{4}$ Università di Palermo, Dipartimento di Ingegneria Chimica, Gestionale, Informatica, Meccanica, Palermo, \\ Italy \\ Corresponding Author Email: sergio.casimiro@lneg.pt
}

Keywords: Parallel MED, desalination, model, concentrated solar power; thermodynamic simulation; cogeneration; TRNSYS

\begin{abstract}
This work presents an overlook on a new model that simulates the physical operation in steady-state of a Multi-Effect Distillation (MED) plant with Parallel-feed (P) configuration. This model includes the consumption of steam with steam ejectors, and its validation was done using data from a real MED industrial plant using a Thermal Vapor Compressor (TVC) operating in Italy, in the Sicilian city of Trapani. Results show that the MED model returns accurate predictions of the plant behavior, very useful for a first analysis on such type of investments. This MED model was also integrated into the System Advisor Model (SAM) developed by the US National Renewable Energy Laboratory (NREL). Simulations with this new tool were run using the location of Trapani as case study for a Concentrating Solar Thermal Power (CSP) plant working in cogeneration with a low temperature MED-P plant versus other cooling options available for CSP plants (wet cooling, dry cooling and a once through Sea Water Cooling Circuit (SWCC)). These results were compared with the existing TVC-MED plant, and indicate that CSP+MED has the potential to be economically attractive.
\end{abstract}

\section{Introduction}

Over exploitation of resources and climate changes are making many areas water stressed allaround the globe. Desalination technologies, powered by fossil fuels, have been used as one of the main options to overcome this problem and guarantee a secure supply of fresh water, but at a cost of high energy bills and large $\mathrm{CO}_{2}$ emissions [1].

Combining desalination technologies with sustainable energy sources is one way to offset such drawbacks. CSP is one of such clean technologies that could integrate better with desalination processes. CSP can provide both thermal and electrical power and is one of the few renewable energy sources that can reliably and economically store energy to produce at a constant output (using thermal storage) even when its main resource - solar energy - is insufficient [2]. 
In the present work, a purposely-developed model for the simulation of a CSP-MED integrated plant has been adopted for predicting the operation of a solar powered co-generation plant. The model is based on the well known CSP plant simulator SAM [3], upgraded with a routine for the simulation of a low-temperature MED unit with parallel configuration. This upgrade can also simulate the operation of the MED plant coupled with a TVC system. In the next paragraphs a short description of the MED model implemented will be given along with a first analysis of different operating scenarios of the whole integrated plant.

\section{Steady-State MED Parallel model}

The model describes the mass and heat flow across the several effects of a MED plant in steadystate conditions taking into account both the evaporation and the flashing of brine and distillate when they enter the different chambers within the MED unit. The model can predict the operation of the MED-P plant coupled with a TVC or just using steam at low pressure and temperature (e.g. provided by the exhaust of a condensing steam turbine) to feed the first effect. The main inputs to the model reflect the temperature profile, namely: the top and bottom operating temperatures, the characteristics of the seawater and steam entering the plant (temperature and salinity), the number of effects and the salinity of brine produced in the first effect. The main outputs are: the flow rates and salinities of the different streams flowing within the MED plant along the several stages, the heat load inside the effects and preheaters, the mass flow of steam used to operate the NonCondensable Gases (NCG) ejectors, the mass of entrained vapor from the last effect if a TVC is assumed to exist, the intermediate temperatures used inside the: distillate boxes, shell side of the effects and mass flows leaving the plant.

Currently the model does not include detailed calculations for pressure losses during the vapor flow in the demisters, vapor transmission lines and vapor condensation inside the tube bundles. The user can set a fixed percentage for thermal energy losses that is applied to each effect. A similar user defined input was also set for the vapor temperature output from each effect. As the model does not calculate in detail heat losses and subcooling during heat transfer in the tube bundles, these variables were introduced in the code so that the user could have some degree of control over the expected losses and subcooling when simulating an MED plant.

The objective of creating a detailed MED-P model was to integrate it into another model that simulates the operation of CSP plants, as CSP plants have inherently a higher degree of intermittence of operation when compared to fossil fuel power plants. Due to the potential small startup times for MED plants from hot standbys (ranging from 30 minutes to 1 hour), it was considered that a steady-state model could return good results, especially if the MED plant could be downsized compared with the CSP plant installed capacity in order to operate the MED plant more frequently near design conditions.

\section{a. Overview of Mathematical model and Algorithm}

A scheme with the bulk of the MED-P process described in this work is presented in figure 1. 


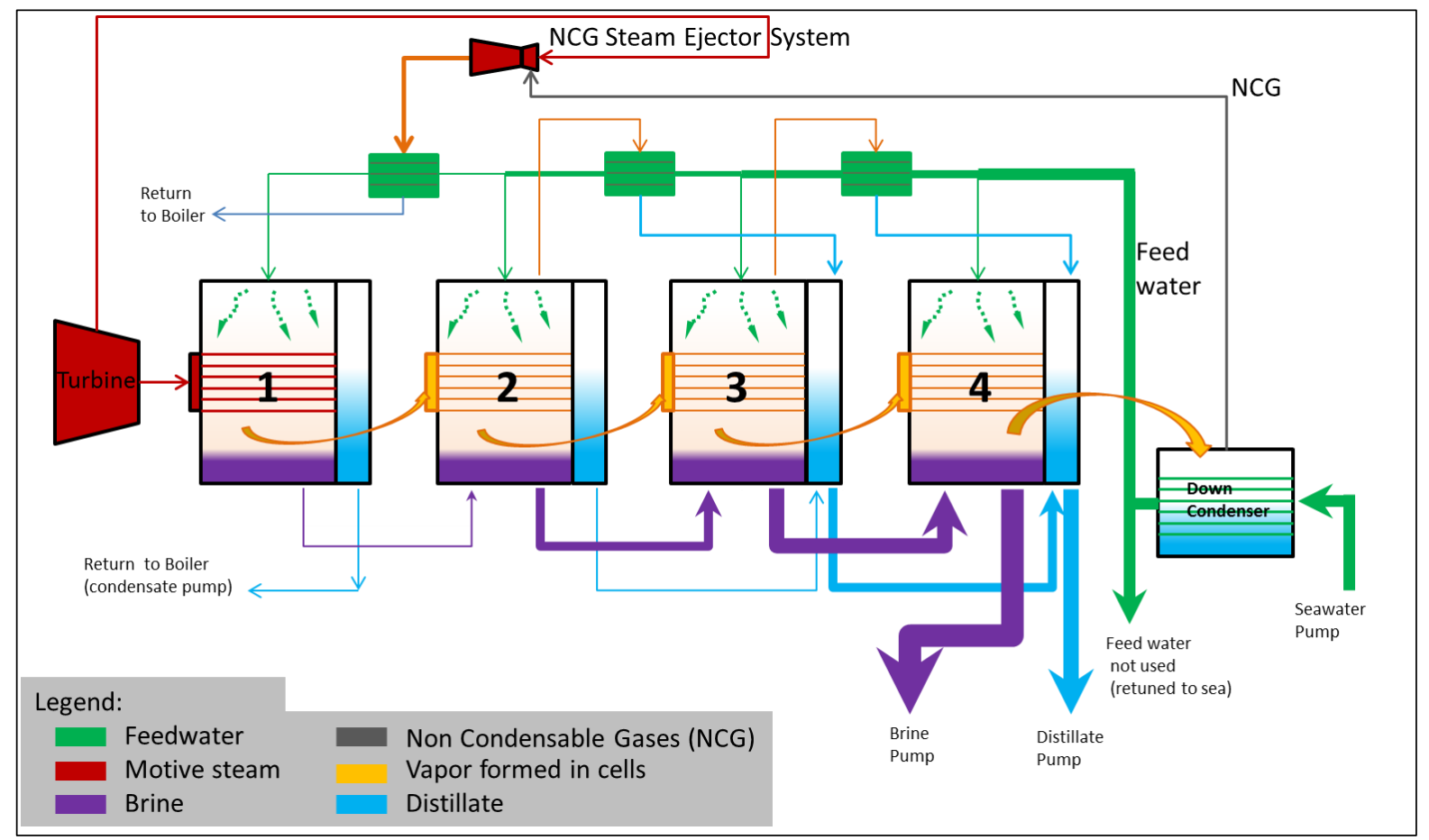

Figure 1 - Scheme of the MED-P process described in this work.

The temperature and pressure profile used to run the model are set assuming an equal difference between vapor temperature of adjacent effects, knowing the top and bottom operating temperatures and the number of effects (in this work, subscripts next to variables refer to the number of effects, e.g. $\operatorname{Tf}_{(1: 2)}$ refers to the feedwater temperature that enters effects 1 to 2 ).

$$
\text { Delta_Tv }=\left(\operatorname{Tv}_{(1)}-\operatorname{Tv}_{(\mathrm{n})}\right) /(\mathrm{n}-1)
$$

The boiling temperatures are calculated from the vapor temperature in each effect. As it concerns the calculation of the brine temperature, the Boiling Point Elevation (BPE), has been estimated assuming the salinity of all the evaporation effects in the plant to be equal to the salinity in the first one. This is an approximation, as at this stage, the salt balance for each effect has not been calculated. In practice the variability of $\mathrm{Xb}$ will be relatively small from the first to the last effect $(\sim 1 \mathrm{wt} \%)$, which means that the variation of $\mathrm{Tb}$ using a correct $\mathrm{Xb}$ versus this approximation $\mathrm{Xb}_{(1)}$ will be around $0.12^{\circ} \mathrm{C}$, and it is assumed to be negligible for the calculation of the BPE.

$$
\mathrm{Tb}_{(\mathrm{i})}=\mathrm{Tv}_{(\mathrm{i})}+\operatorname{BPE}\left(\mathrm{Tv}_{(\mathrm{i})}, \mathrm{Xb}_{(1)}\right)[4]
$$

This model allows the user to define the configuration of the preheaters throughout the plant. The user can define if the preheaters are placed between every effect or between every 2 effects. It is always assumed in both configurations that there are no preheaters between effects that receive feedwater preheated by the intercondensers of the Non Condensable Gases (NCG) steam ejectors system. The temperature profile of the feedwater across effects is calculated in all effects assuming they will have the same temperature difference than in the last effect between the feedwater and the vapor temperature.

$$
\mathrm{Tf}_{\left(1: \mathrm{n} \_\mathrm{ph} \_\mathrm{NCG}\right)}=\mathrm{Tb}_{\left(\mathrm{n} \_\mathrm{ph} \_\mathrm{NCG}\right)}-\text { Delta_Tf_iph }
$$


The user can also define that no preheaters are installed, being only considered the existence of a down condenser. In this case, all effects receive feedwater at the same temperature.

The first effect is the hottest, and has the highest potential for work compared with the remaining effects (if the plant is assumed to have preheaters attached to every effect).

In this model not all the heat flowing into each effect is used directly in the evaporation process. Depending on the preheaters configuration throughout the plant, the heat load powering an effect may actually be higher than the previous one that operates at higher temperature. Such can happen for example if the preheaters are positioned between every two effects.

This MED model assumes that the vapor formation inside the effects occurs due to the physical processes of evaporation and flashing. These take place on the external surface of the heat exchanger tubes (in the shell side of each evaporator), on the brine pool, and inside the distillate boxes.

Most of the heat load powering each effect is the result of the mass of vapor that was not used in the previous effect to preheat the feedwater (internally, and externally if a preheater receives vapor from the previous effect). To compensate these losses with the preheating, the masses of brine and distillate produced in each effect are routed into the subsequent effect. As the masses of brine and distillate enter the next effect, part of them will flash and create more vapor.

The energy released during the flashing process is equal to the enthalpy decrease of the flashing solution (namely the brine or distillate). This energy is released mainly by the water molecules near the liquid surface, as they overcome the surrounding hydrostatic pressure and surface tension, decreasing the liquid temperature [5], [6]. This energy release is equal to the latent heat necessary to evaporate water at the saturation temperature at which the vapor will be formed in the chamber.

$$
\begin{aligned}
& \text { V_b_flash }_{(\mathrm{i})}=\mathrm{B}_{(\mathrm{i}-1)} *\left(\mathrm{Hb}_{-}\right. \text {Tb_out } \\
& (\mathrm{i}-1) \\
& \text { Qv_b_flash } \\
& (\mathrm{i})
\end{aligned}
$$

As the liquid does not release energy equally across its depth during the time it flows through the chamber where flash occurs, a temperature gradient will be established and a Non Equilibrium Allowance (NEA) will take place, meaning that the temperature at which the water mass will leave the chamber will actually be above the saturation temperature at which the chamber operates.

$$
\begin{aligned}
& \text { DeltaT_b_NEA }_{(\mathrm{i})}=33 *\left(\mathrm{~Tb}_{0} \operatorname{out}_{(\mathrm{i}-1)}-\mathrm{Tb}_{(\mathrm{i})}\right) \\
& \text { Tb_b_flash }_{(\mathrm{i})}=\mathrm{Tb}_{(\mathrm{i})}+\mathrm{Delta}^{(0.5)} / \mathrm{Tv}_{(\mathrm{i})}[5] \\
& \text { De_NEA } \\
& (\mathrm{i})
\end{aligned}
$$

More energy is drained from colder effects to preheat the feedwater (inside the feedwater preheaters) than from upstream effects, due to the reduction of feed water flow rate being preheated from the last to the first effects. However, since the brine and distillate increase their volume as they move along the stages, the heat load from flashing also increases (although it does not compensate totally the energy used for preheating the feedwater).

The vapor formed by the brine flash is assumed to add up to the vapor formed by evaporation of the feedwater in each effect. The superheated part of the vapor formed by brine flashing is assumed to be used for the feedwater preheating inside the effect.

$$
\mathrm{V}_{(\mathrm{i})}=\mathrm{V} \_\operatorname{evap}_{(\mathrm{i})}+\mathrm{V} \_ \text {b_flash }(\mathrm{i})
$$


The heat load passing into each effect in this model is assumed to correspond to the latent heat released by the vapor condensation inside the heat transfer tube bundle.

$$
\mathrm{Q}_{(\mathrm{i})}=\mathrm{V}_{(\mathrm{i})} * \mathrm{LHv}_{-} \operatorname{evap}_{(\mathrm{i})}
$$

If a TVC is used, the model assumes the existence of a desuperheater between the TVC and the first effect of the MED plant. In this case the heat load passing into the first effect is calculated by using the difference between enthalpies of the slightly superheated steam leaving the desuperheater and the subcooled distillate formed inside the heat transfer tube bundle of the first effect. The superheated steam entering the first effect and the corresponding subcooled distillate that is produced are assumed to be at the same pressure. This pressure is calculated based on the saturated temperature of the steam leaving the TVC (note that it is assumed that the steam leaving the TVC will be superheated but at a pressure defined by the saturated temperature).

The pressure inside of the distillate box is defined in this model by the temperature of the steam being condensed inside the heat transfer tube bundle. This pressure is equal to the pressure inside the previous effects minus the average pressure loss predefined when the vapor crosses the tube bundles. The user can set an average temperature loss of the steam entering the tube bundles, and from that value a pressure loss is calculated assuming saturated conditions.

The distillate boxes collect distillate from different sources, namely: the intercondensers from the NCG ejection system, the outlet from the main tube bundles, and the previous effect distillate box. When entering the distillate boxes these mass flows will be at different temperatures and pressures, and so flashing will occur. Most of this flashing will be related to the distillate flowing from the previous effect, but a small amount will be from the condensate returning from the NCG ejection system intercondensers into some of the first effects (that are immediately downstream of these intercondensers).

The model incorporates also a database describing the performance of steam ejectors for different pressures of motive steam, entrainment and discharged gases obtained from one of the main manufacturers of steam ejectors for MED plants. In this model the NCG ejection system is considered to have two ejectors. The positioning of the ejectors intercondensers can be defined by the user, but it is always considered that the effects upstream of these two intercondensers do not have more external preheaters of any kind.

Both intercondensers of the NCG ejection system are modeled to provide the maximum amount of heat possible into the MED plant, being limited by the maximum compression ratio for their size. The first ejector is dimensioned in this model to provide the maximum energy possible without over-dimensioning the amount of NCG assumed to be ejected. If the first NCG ejector cannot provide enough energy to the feedwater and obtain the same temperature increase that was assumed for the previous feedwater preheaters, then the model will assume a lower temperature output from the preheated feedwater of the first NCG steam ejector. The second NCG ejector will aim at a user defined temperature output for its intercondenser cooling water output, and so the model may overdimension the amount of NCG ejected by this ejector, in case the maximum energy input into it is not enough (having into account the maximum compression ratio for the selected pressures with this ejector). Currently the database available to this model for the calculation of the steam ejectors performance is limited to steam pressures between 8 and 12 bars, but it may be expanded in the future.

For an MED-P low temperature configuration the model considers that the distillate from the first and second intercondensers of the NCG ejection system will enter the first effect downstream to the intercondensers position. The condensate formed by the first intercondenser is considered to be at the same saturated vapor temperature at which the distillate box operates, and so it will not flash. 
Only the condensate from the second intercondenser is assumed to be at a higher temperature than the distillate box, and it will flash when entering it.

The salinity of the brine produced in the first effect is an input. This input is necessary to define the evaporation ratio and to calculate how much energy is transferred into subsequent effects. The mass flow of feedwater entering each effect is considered to be equal to the flow rate necessary to enter the first effect (in order to guarantee equal wetting areas in all effects, especially during part load operation, as the heat transfer areas will be equal across effects in most industrial MED plants).

The salinity profile throughout the effects is calculated having into account the heat flow entering each effect and the mass flow of feedwater. The effects will have different heat loads, but a similar inlet feedwater mass flow rate. Thus, the evaporation ratio and brine salinity in each effect will also differ. From the second effect onwards, the brine salinity of the previous effect is used as guess value to calculate the evaporation ratio. Then, using a small loop for each effect, if the heat flow coming from the previous effect is higher than the one required to reach the initial guess value for the evaporation ratio a higher brine salinity is set. If the heat flow coming from the previous effect is lower, a lower brine salinity is set. The loop runs until the equilibrium is reached, i.e. the heat flow entering the effect matches the energy required to evaporate the feedwater to the new (recalculated) evaporation ratio.

$$
\begin{aligned}
& \mathrm{D}_{(\mathrm{i})}=\mathrm{F}_{(\mathrm{i})} *\left(\mathrm{Xb}_{(\mathrm{i})}-\mathrm{Xf}\right) / \mathrm{Xb}_{(\mathrm{i})} \\
& \mathrm{Q}_{(\mathrm{i})}=\mathrm{F}_{(\mathrm{i})} *\left(\text { Delta_H_iph }_{(\mathrm{i})}+\mathrm{LHv}_{-} \operatorname{evap}_{(\mathrm{i})} *\left(\mathrm{Xb}_{(\mathrm{i})}-\mathrm{Xf}\right) / \mathrm{Xb}_{(\mathrm{i})}\right)
\end{aligned}
$$

The heat load passing into each effect:

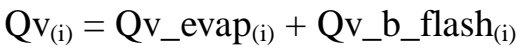

$$
\begin{aligned}
& \text { Qv_remain_after_preheating }{ }_{(\mathrm{i})}=\mathrm{Qv}_{(\mathrm{i})}-\mathrm{Q} \_\mathrm{eph}_{(\mathrm{i})}
\end{aligned}
$$

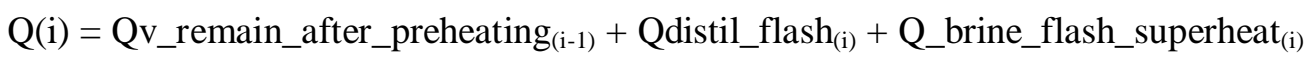

This model also accounts parasitic consumption with the MED plant (except the impact on the electrical production of intermediate steam extractions from the steam turbine to remove NCG from the MED system). The parasitic consumptions accounted are the pumping of: seawater into the plant, brine back to the sea, distillate storage, and brine and distillate out of the last effect.

\section{b. Validation of the model}

The MED-P system considered in this paper is based on the industrial TVC - MED-P plant that operates nearby the Sicilian city of Trapani, Italy, since 1995. This plant has four MED trains, each producing $9000 \mathrm{~m}^{3} /$ day with the aid of a TVC in each unit. The TVC's are powered by steam at 45 bars produced by 2 dedicated boilers burning natural gas [7], [8], [9]. In this work only the bulk of the MED-P process can be validated with data from the real plant. The part of the model that calculates the operation of the TVC and NCG ejectors cannot be accurately compared yet as the Trapani plant uses motive steam at 45 bars and the database available to this MED model only has information for motive steam pressures between 8 and 12 bars. In the near future this database may be expanded, and a validation of the MED parallel model including the code describing the TVC and NCG will be conducted.

Because of this, the validation of the MED model was done using the total mass flow of vapor entering the first evaporator of the MED plant, pre-setting the temperature of the feedwater entering the first 2 effects and the mass of motive steam used by the NCG ejection system. 


\section{i. Input data for Validation:}

The main inputs for nominal design conditions used to validate the model are presented in table 1 (pressure losses and subcooling of the condensate during the heat transfer inside the tube bundles were considered to be zero for the validation process).

Table 1 - Main inputs to the MED model for the validation process [7], [8]

\begin{tabular}{lll}
\hline Parameter & Value & Units \\
\hline $\mathrm{Ts}_{\text {_sat }}$ & 84.0 & ${ }^{\circ} \mathrm{C}$ \\
$\mathrm{Tv}_{(1)}$ & 62.2 & ${ }^{\circ} \mathrm{C}$ \\
$\mathrm{Tv}_{(\mathrm{n})}$ & 37.0 & ${ }^{\circ} \mathrm{C}$ \\
$\mathrm{Tf}_{(1: 2)}$ & Nominal design conditions & ${ }^{\circ} \mathrm{C}$ \\
$\mathrm{Tf}_{(\mathrm{n})}$ & 35.0 & ${ }^{\circ} \mathrm{C}$ \\
$\mathrm{Me}$ & Nominal design conditions & $\mathrm{kg} / \mathrm{s}$ \\
$\mathrm{Mm}$ & 6.25 & $\mathrm{~kg} / \mathrm{s}$ \\
$\mathrm{E} \_\mathrm{Mm}$ & 0.42 & $\mathrm{~kg} / \mathrm{s}$ \\
$\mathrm{Xf}$ & 4.0 & $\mathrm{wt} \%$ \\
$\mathrm{Xb}$ & Nominal design conditions & $\mathrm{wt} \%$ \\
$\mathrm{~N}^{\circ}$ of effects (n) & 12 & - \\
\hline
\end{tabular}

\section{ii. Results outputs:}

The main results are shown in table 2, where real data collected from the MED plant in Trapani is compared with the results from the model for four crucial operating variables, namely: Feedwater flow rate, distillate flow rate, brine flow rate and salinity of the output brine.

Table 2 - Main output results using inputs for design conditions at the Trapani TVC-MED-P plant

\begin{tabular}{lllllll}
\hline Parameter & \multicolumn{2}{l}{ Real data $[7]$} & \multicolumn{2}{l}{ Modeled } & \multicolumn{2}{l}{ Difference } \\
\hline Feedwater & 1130 & $\mathrm{~m}^{3} / \mathrm{h}$ & 1216 & $\mathrm{~m}^{3} / \mathrm{h}$ & 7.6 & $\%$ \\
Distillate & 375 & $\mathrm{~m}^{3} / \mathrm{h}$ & 390 & $\mathrm{~m}^{3} / \mathrm{h}$ & 4.0 & $\%$ \\
Brine & 755 & $\mathrm{~m}^{3} / \mathrm{h}$ & 825 & $\mathrm{~m}^{3} / \mathrm{h}$ & 9.3 & $\%$ \\
Salinity output & 5.99 & $\mathrm{wt} \%$ & 5.88 & $\mathrm{wt} \%$ & -1.8 & $\%$ \\
\hline
\end{tabular}

Interestingly, model predictions fit well the experimental data from the plant, with discrepancies laying within a $10 \%$ margin of error when comparing with the design conditions for this plant. Such a small difference can be attributed to some secondary simplifying assumptions adopted within the model formulation. In fact, though the model details in a large extent the different mass flow paths through the different chambers within effects and preheaters, it does not calculate pressure losses 
during the vapor flow in the demisters, vapor transmission lines and vapor condensation inside the tube bundles. Moreover, no subcooling is being assumed during the heat transfer process in the tube bundle inside the several effects (as all the effects have the same heat transfer area, this subcooling process will progressively decrease along the effects chain, reaching its minimum in the last effect).

\section{CASE study:}

\section{a. Description of the CSP+MED system}

The studied CSP+D system consisted in a $110 \mathrm{MW}_{\mathrm{e}}$ parabolic trough CSP plant with a rankine cycle coupled with a low temperature MED parallel-feed plant. By considering a low temperature MED plant, the case study assumes that the electrical power generated would be the main product of the cogeneration process and the distillate produced the subproduct. Figure 2 presents a general schematic of the CSP+MED/SWCC cogeneration system assumed for the case study.

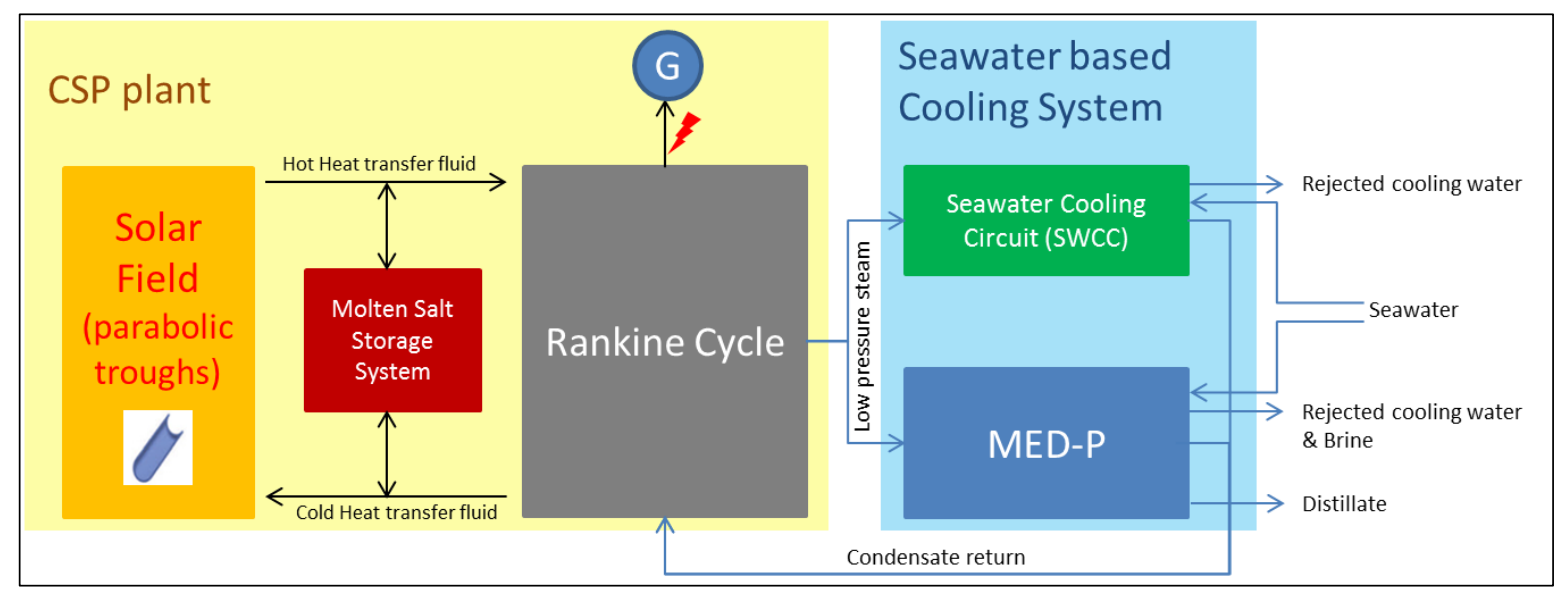

Figure 2 - general schematic of the CSP+MED/SWCC system

The thermodynamic simulation for the CSP plant was done using the SAM's physical trough system [3] developed in TRNSYS environment (TRNSYS is a commercial software package designed for simulation of transient systems). A controller had already been developed to combine the usage of a CSP plant with CSP troughs and an MED forward feed low temperature plant previously in [10], and this work uses the same controlling strategy and controller (updated). This configuration assumes the existence of a SWCC connected to the CSP-MED plants, which is dimensioned to absorb the entire amount of the rejected heat by the CSP plant at design conditions. The MED plant can be undersized regarding the reference value of $100 \%$ for the nominal heat load output from the CSP plant (this is a user defined input), with the aim of improving the MED plant performance during part load operation of the CSP plant. During the startup of the MED plant in the simulation, the SWCC is assumed to take over the cooling process. If both a MED and a SWCC are considered to exist, then the SWCC will operate at the same condenser pressure than the MED. The MED plant will only start operating above a user determined percentage of heat load output from the CSP plant (compared to its nominal value), and below that, the SWCC takes over the cooling process. The user can also define the startup period for the MED plant. The MED during the simulations is not assumed to shut down completely, and only hot standbys are considered. The CSP plant on the other hand is assumed to be able to shut down completely or be maintained in hot standby during a user defined amount of time. 
The model used for this simulation can calculate the amount of motive steam used to eject NCG. It is important to mention though that its impact is not yet reflected in the electrical output of the power cycle in SAM. This will addressed in future works.

\section{b. Main Parameters used in the simulation}

The weather data used for the simulations in Trapani was gathered from 2 sources: Meteonorm 5.1 database available with TRNSYS 16, and [11] using satellite data from the year of 1997. The main inputs used for the Trapani simulation in SAM with the MED-P add-on are described in table 3. The CSP configuration used was based on the standard configuration presented in SAM when the physical trough model is selected. The main changes consist on the hours of thermal storage available, installed power, solar multiple and weather file used.

Table 3 - Main inputs used for the Trapani simulation in SAM

\begin{tabular}{lll} 
CSP plant & Value & Units \\
\hline Installed CSP Power (trough using oil as HTF): & 99 net & MWe \\
& $(110$ gross) & Hours \\
Thermal Storage with Molten Salts & 13 & $\%$ \\
Rated cycle conversion efficiency: & 37.74 & ${ }^{\circ} \mathrm{C}$ \\
Condenser temperature for Rated Cycle conversion efficiency & 35 & - \\
Solar multiple $*$ & 3 & $\mathrm{~W} / \mathrm{m}^{2}$ \\
Irradiation at design (reaching the solar field) & 950 & $\%$ \\
Solar collector loop conversion efficiency (Solargenix SGX-1) & 71.69 & ${ }^{\circ} \mathrm{C}$ \\
Inlet temp (outlet boiler) & 391 & ${ }^{\circ} \mathrm{C}$ \\
Outlet temp (inlet boiler) & 293 & $\mathrm{Bar}$ \\
Boiler pressure & 100 & $\mathrm{Hours}$ \\
Hot Standby period & 2 & $\%$ \\
Fraction of thermal power for standby & 20 & $\%$ \\
Turbine overdesign & 105 & $\%$ \\
Turbine Minimum & 25 & ${ }^{2}$ \\
Direct Normal Irradiation (DNI) & $2004[11]$ & $\mathrm{kWh} / \mathrm{m}^{2} / \mathrm{yr}$ \\
Saturated temperature Turbine Outlet & 64.5 & ${ }^{\circ} \mathrm{C}$ \\
Fossil fill fraction ${ }^{\dagger}$ & 0 & ${ }^{\circ}$ \\
\hline
\end{tabular}

MED

Total number of effects (n) $\mathrm{n}=12$

MED designed fraction compared to CSP heat load output

40 $\%$

Intake distance [7] 
Saturated Steam powering MED

$64.5 \quad{ }^{\circ} \mathrm{C}$

Seawater temperature [7]

10 (Jan); 22 (Jul) $\quad{ }^{\circ} \mathrm{C}$

Xf [7]

4

Hot Restart time

100

wt\%

Overdesign (Max. operation)

$110 \%$

Min. operation

20

$\%$

$\mathrm{Tv}_{(1)}[7]$

62.2

${ }^{\circ} \mathrm{C}$

$\mathrm{TV}_{(\mathrm{n})}[7]$

$37 \quad{ }^{\circ} \mathrm{C}$

$\operatorname{Tf}_{(\mathrm{n})}[7]$

35

${ }^{\circ} \mathrm{C}$

Motive steam pressure used with NCG ejection system

8

bars

Average heat loss per effect

$\%$

SWCC

\begin{tabular}{lll}
\hline Pressure required at the condenser outlet (CSP+SWCC only) & $1 \times 10^{5}$ & $\mathrm{~Pa}$ \\
Temperature approach & 5 & ${ }^{\circ} \mathrm{C}$ \\
Condensation temperature (CSP+SWCC only) & 40 & ${ }^{\circ} \mathrm{C}$ \\
\hline
\end{tabular}

Dry Cooling

\begin{tabular}{lll}
\hline Minimum condenser pressure & 2 & inHg \\
Initial Temperature difference at design & 16 & ${ }^{\circ} \mathrm{C}$ \\
\hline
\end{tabular}

Wet Cooling

\begin{tabular}{lll}
\hline Minimum condenser pressure & 1.25 & inHg \\
Approach temperature & 5 & ${ }^{\circ} \mathrm{C}$ \\
\hline
\end{tabular}

* Solar multiple is the solar field aperture area expressed as a multiple of the aperture area required to operate the power cycle at nominal capacity. The aperture area is the total solar energy collection area of the solar field in square meters, and it is less than the total mirror surface area (as the mirrors are curved, with a parabolic shape). The aperture area is calculated by dividing the solar field thermal output at design by both the irradiation at design $\left(\mathrm{W} / \mathrm{m}^{2}\right)$ and the conversion efficiency specifications for the chosen solar collector loop. The calculation of the solar field thermal output at design $\left(\mathrm{MW}_{\mathrm{t}}\right)$ is made by dividing the gross electric installed capacity $\left(\mathrm{MW}_{\mathrm{e}}\right)$ by the nominal cycle rated efficiency [3].

$\dagger$ fraction of the power, at nominal capacity, that can be generated by the aid of a backup boiler fed with conventional fossil fuel.

$\$ 100$ minutes is a conservative estimate for a hot startup of an MED plant. An optimistic approach would be just above $\sim 30$ minutes. 


\section{c. Outputs}

Several simulations were run for the location of Trapani to dimension the CSP+MED-P plant operating in cogeneration. Independently of the installed capacity for thermal storage and solar multiples assumed (within reasonable ranges), using only the solar resource it would not be possible to run continuously the CSP and/or the MED plants during winter time because the solar resource would simply not be enough.

The CSP+MED plant configuration was set for the simulation so that at least between May and August the CSP capacity factor would be between 55\% and 65\%, and the MED near 80\% (thus increasing the number of days where both the CSP and MED plants would operate continuously during 24 hours). Using the selected configuration of 13 hours of storage and solar multiple of 3 , the CSP and the MED yearly capacity factors are $34.2 \%$ and $41.4 \%$, respectively. The levelized cost of electricity (LCOE) could not be used as a metric to optimize the size of the solar field as economic costs and selling prices were not accounted in this work. Table 4 shows the general performance characteristics of the CSP and MED plants (when working in cogeneration), and the maximum and minimum main operating values when compared with nominal conditions. As expected, the Performance Ratio (PR) reaches 10.2, just below the number of effects of the MED plant (12). A conservative approach was used for the MED hot startup time. Using the same plant configuration, if an optimistic approach would be assumed for the MED hot startup times ( 30 $\mathrm{min}$ ), then the yearly capacity factor of the MED plant would increase from $41.4 \%$ to $44.9 \%$.

Table 4 - General performance characteristics of the CSP+MED/SWCC plants for the Trapani simulation

\begin{tabular}{lll}
\hline Metric & Value & Units \\
\hline Time Step used & 1 & Hours \\
Nominal MED production capacity & 36112 & $\mathrm{~m}^{3} / \mathrm{day}$ \\
Total MED production & 5454052 & $\mathrm{~m}^{3} / \mathrm{year}$ \\
Potential MED production & 13180707 & $\mathrm{~m}^{3} / \mathrm{year}$ \\
Nominal Heat load MED & 87.1 & $\mathrm{MW}_{\mathrm{t}}$ \\
Minimum MED load & 17.4 & $\mathrm{MW}_{\mathrm{t}}$ \\
Maximum MED load & 95.8 & $\mathrm{MW}_{\mathrm{t}}$ \\
MED Capacity Factor & 41.4 & $\%$ \\
Performance Ratio (PR) & 10.2 & - \\
MED specific electric consumption at design & 2.81 & $\mathrm{kWh}_{\mathrm{e}} / \mathrm{m}^{3}$ \\
CSP NET output at design & 99 & $\mathrm{MW}_{\mathrm{e}}$ \\
CSP design gross output & 110 & $\mathrm{MW}_{\mathrm{e}}$ \\
CSP Capacity factor (net electric) & 34.2 & $\%$ \\
CSP total electric Gross production & 336130 & $\mathrm{MWh}_{\mathrm{e}} / \mathrm{year}$ \\
CSP total electric NET production & 297017 & $\mathrm{MWh}_{\mathrm{e}} / \mathrm{year}$ \\
Potential CSP GROSS elect. & 963600 & $\mathrm{MWh}_{\mathrm{e}} / \mathrm{year}$ \\
\hline
\end{tabular}


Four cooling options were considered when simulating the operation of a CSP plant at Trapani, namely: MED-P/SWCC, dry cooling, evaporative wet cooling (using saltwater), and SWCC without MED.

When analyzing the option of running a CSP+MED-P at Trapani, from figure 3 it is possible to see that the production profile is in line with the typical Mediterranean climate (as the power comes from solar irradiation). Production peaks during summer and decreases sharply during winter time, despite the usage of a CSP plant with a large thermal storage capacity (13 hours) and solar multiple of 3. During summer time, capacity factors are higher (normally above 50\%), and in winter time they are low (below 10\%). In line with this profile is also the rate for CSP plant parasitic consumption. The CSP parasitic consumptions accounted are described in [3] and include: auxiliary boiler parasitic load, fixed parasitic load, balance of plant parasitic load, total parasitic power for tank freeze protection, solar collector assemblies drives and electronics parasitic power, thermal energy storage and power block heat transfer fluid pumping power, collector field required pumping power, power block cooling parasitic power, and collector field required freeze protection. In relation to the gross electrical production, the CSP plant parasitic consumption is especially high between November and January. During these winter months, the anti-freezing protection system for the CSP thermal storage tanks operates more often, as the CSP plant almost does not run (and in a smaller scale, thermal losses in the molten storage tanks are also higher than in summer time as air temperatures are lower).

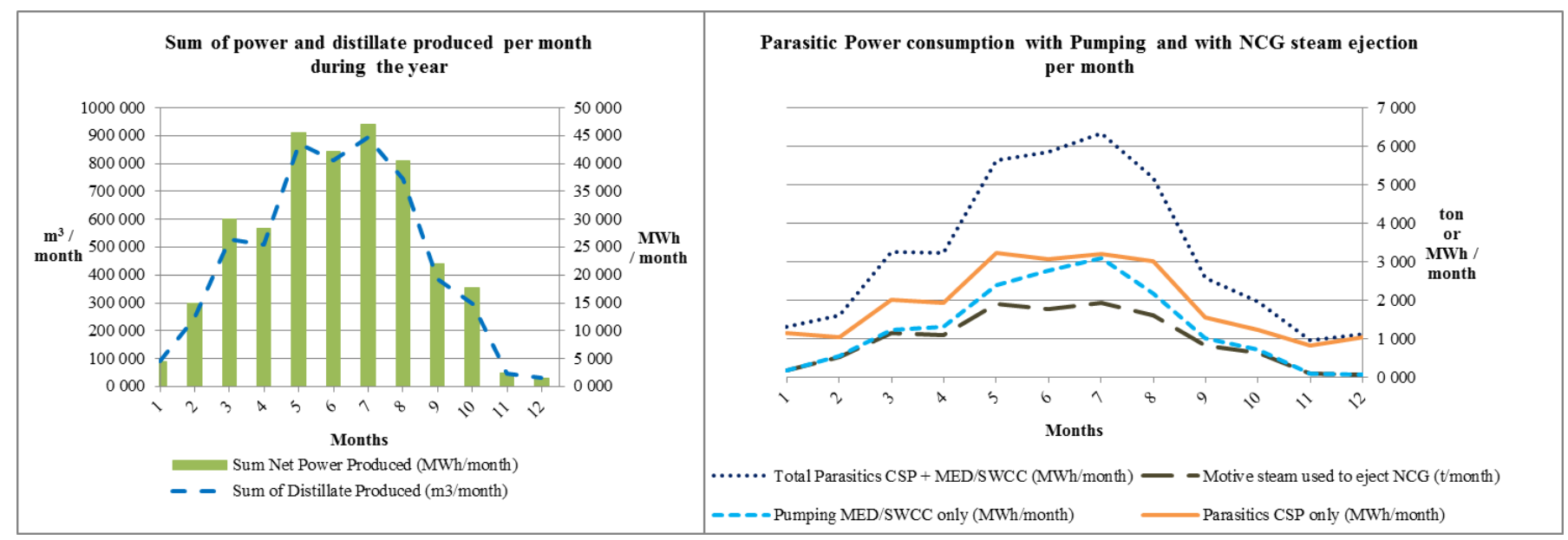

Figure 3 - Cumulative production and parasitic of the CSP+MED/SWCC for a one year operation

In figure 4 it is possible to see the detailed outputs of the CSP+MED/SWCC operation for a typical day during winter ( $3^{\text {rd }}$ of January) and summer ( $1^{\text {st }}$ of July).

During this winter day the operation of both plants is only possible during a few hours because the solar resource is scarce. It is possible to see also that during this day the SWCC system absorbs the variability of the CSP output, enabling the MED to operate during those few hours near nominal conditions. The slight increase in production of the MED plant between 14:00 and 15:00 is due to the MED startup time getting completed only during this time step, and so the nominal production will occur just for a percentage of this time step (time steps in this simulation represent 1 hour).

On the $1^{\text {st }}$ of July the panorama is totally different, as the solar resource is higher and the CSP plant can operate continously using the thermal storage tanks to provide heat to power the rankine cycle during the hours with insufficient solar irradiation. A 24 hour operation is possible during this 
summer day as the CSP plant was fit with a large thermal storage capability and an adequate solar multiple for the solar field. As consequence, the MED plant can also operate uninterruptly during this period. Again, it is possible to notice that the SWCC absorbs the variability of the rejected heat load coming from the CSP plant allowing the MED plant to operate at a constant load.

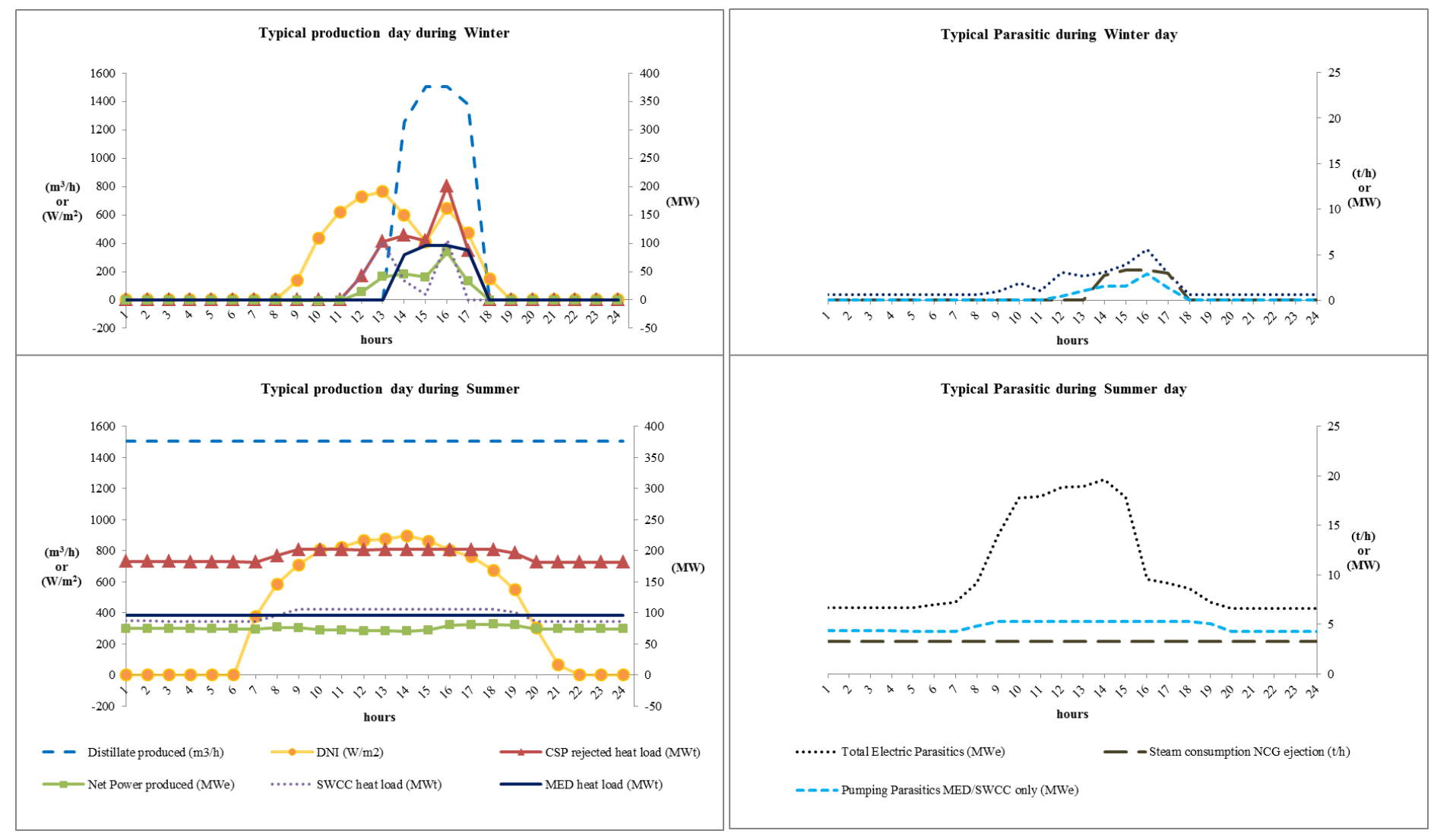

Figure 4 - Typical operation days for a CSP plant with MED/SWCC during winter ( $3^{\text {rd }}$ of January) and summer time $\left(1^{\text {st }}\right.$ of July)

Figure 5 shows a comparison of electrical generation for all scenarios taking as a reference the power output of the CSP+MED/SWCC system. The scenario with the highest electrical production is obtained when using the CSP plant with wet cooling, followed by the CSP with SWCC. In average the CSP plant using wet cooling or the SWCC configurations produces $\sim 30 \%$ more electricity than the CSP+MED/SWCC configuration, and dry cooling produces more $\sim 22 \%$. On the other side, the CSP+MED/SWCC allows the production of $\sim 5.4$ million $\mathrm{m}^{3} /$ year of fresh water.

Wet cooling using "saltwater" versus "fresh water" has a negligible difference in performance, although the operation in the long run with saltwater will be more costly due to a faster degradation of the plant components [12]. In this simulation the performance of a CSP+SWCC is slightly below $\mathrm{CSP}+$ Wet Cooling because of the relative high condensation temperature forced to the SWCC, and the distances and depth from which the seawater is assumed to be pumped from the sea in this simulation (the SWCC would have a better performance if a lower condensation temperature would be considered and the intakes would be near the plant). Dry cooling is dependent on the dry bulb temperature, implying higher temperatures in the down condenser of the rankine cycle (yearly average of $42.6^{\circ} \mathrm{C}$ with dry cooling versus $40^{\circ} \mathrm{C}$ with $\mathrm{SWCC}$, and $33.6^{\circ} \mathrm{C}$ with wet cooling). 
CSP and MED production during winter months is much lower than in summer time. There are several days during this period in which the CSP plant will not start at all or it will only operate at a very low capacity below the minimum for the MED operation. As the CSP plant in these conditions will operate near its minimum load, in some cases the CSP+MED/SWCC system may not start at all while the CSP with other cooling options (with higher performance) would still operate. The total yearly electrical output will not suffer much with these performance differences during winter time, but when analyzing graphics showing outputs in relative percentages, large differences during winter months may appear between performance curves.

In theory the CSP+SWCC configuration will have less parasitic consumption with water pumping than CSP+MED/SWCC as the MED plant will use more seawater to reject the same amount of heat load from the CSP plant (and in this simulation the MED is set to receive a higher temperature outlet from the low pressure turbine than the SWCC). The CSP+SWCC configuration increases its performance relative to the CSP+MED/SWCC through the warmer season of the year (April up to September, regarding the net electrical production only) as during these months the CSP plant will operate more hours above the minimum load for the MED plant to start. For these situations below minimum loads, in both configurations the CSP plant will operate in practice only with the SWCC (as the MED will not be turned on). In the summer time as the heat load provided by the CSP plant increases in power and time span, the MED plant will operate more often, and the parasitic consumptions will increase compared to the SWCC usage only. Table 5 shows the detailed results of the simulations for the Trapani case study.

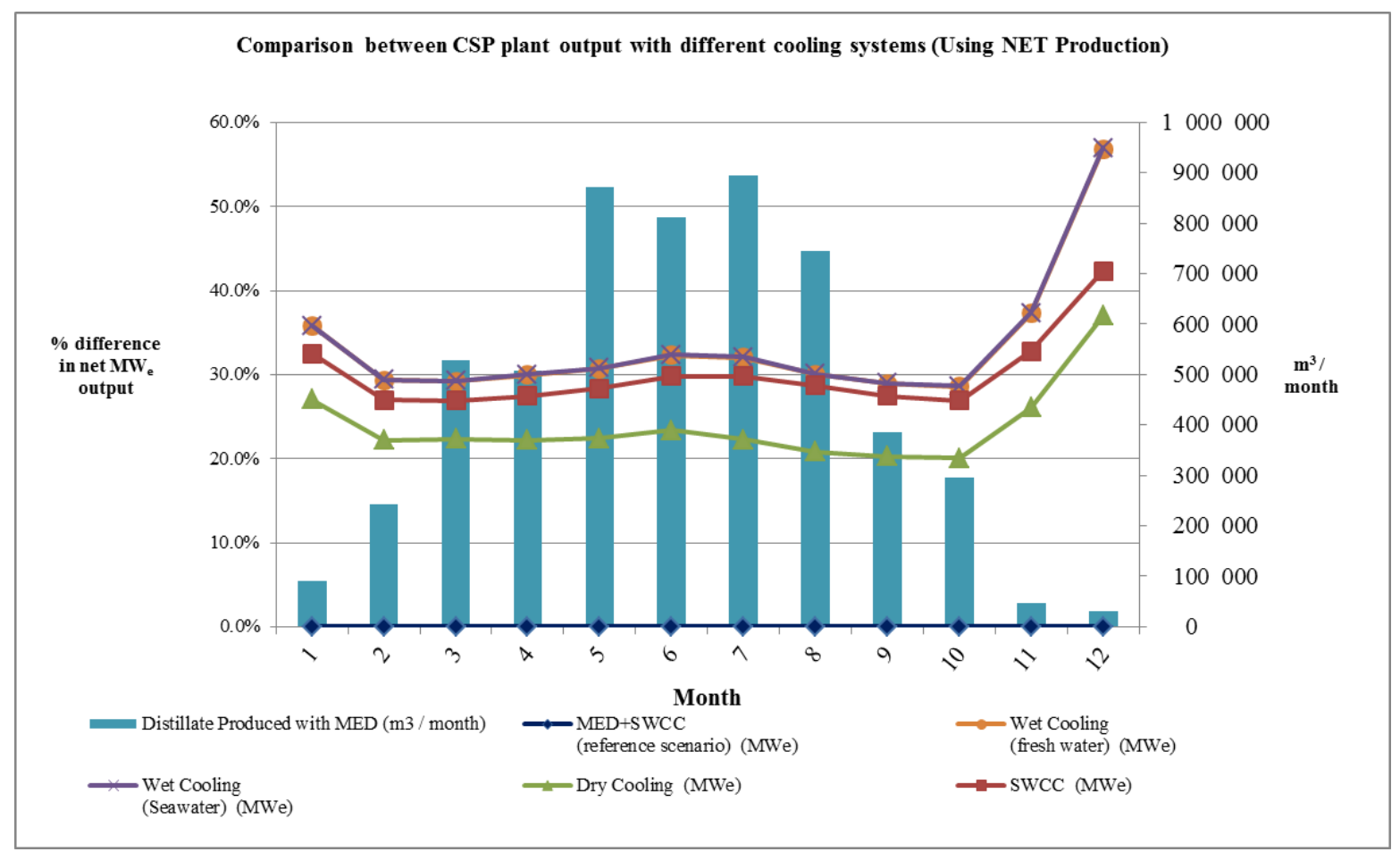

Figure 5 - Comparative power output for the CSP plant with different cooling systems (and distillate production when MED is used) 
Table 5 - Annual and monthly sum of net electrical output, parasitic consumption (except with NCG extraction from the MED system), and distillate produced when the MED is used

\begin{tabular}{|c|c|c|c|c|c|c|c|c|c|}
\hline & \multicolumn{3}{|c|}{ MED+SWCC (ref. scenario) } & \multirow{2}{*}{\multicolumn{2}{|c|}{$\begin{array}{l}\text { Dry Cooling } \\
\text { MWh }_{\mathrm{e}}\end{array}$}} & \multirow{2}{*}{\multicolumn{2}{|c|}{$\begin{array}{l}\text { Wet Cooling (Seawater) } \\
\qquad \mathrm{MWh}_{\mathrm{e}}\end{array}$}} & \multirow{2}{*}{\multicolumn{2}{|c|}{$\begin{array}{l}\text { SWCC } \\
\mathrm{MWh}_{\mathrm{e}}\end{array}$}} \\
\hline & \multicolumn{2}{|c|}{$\mathrm{MWh}_{\mathrm{e}}$} & & & & & & & \\
\hline & Net Elect. & Parasit. & Distillate & Net Elect. & Parasit. & Net Elect. & Parasit. & Net Elect. & Parasit. \\
\hline Jan & 4516 & 1330 & $90 \quad 254$ & 5736 & $\begin{array}{ll}1 & 307\end{array}$ & 6135 & 1217 & 5985 & 1170 \\
\hline Feb & 14921 & 1614 & 243193 & 18236 & 1465 & 19306 & 1238 & 18948 & 1137 \\
\hline Mar & 30133 & 3266 & 528782 & 36864 & 2837 & 38947 & 2364 & 38232 & 2204 \\
\hline Apr & 28418 & 3245 & 508286 & 34728 & 2745 & 36939 & 2293 & $36 \quad 220$ & 2138 \\
\hline May & 45504 & 5635 & 871779 & 55712 & 4733 & 59503 & 3942 & $58 \quad 420$ & 3643 \\
\hline Jun & $42 \quad 172$ & 5858 & 811590 & $52 \quad 027$ & 4873 & 55818 & 3871 & 54751 & 3566 \\
\hline Jul & $47 \quad 104$ & 6331 & 894711 & $57 \quad 603$ & 5592 & $62 \quad 213$ & 4198 & $61 \quad 138$ & 3769 \\
\hline Aug & $40 \quad 473$ & 5193 & $745 \quad 426$ & 48902 & $\begin{array}{ll}5 & 147\end{array}$ & $52 \quad 645$ & 3939 & $52 \quad 080$ & 3380 \\
\hline Sep & 22049 & 2591 & 385899 & 26518 & 2616 & 28434 & 1990 & 28100 & 1714 \\
\hline Oct & 17776 & 1966 & 296229 & 21346 & 2000 & 22862 & 1533 & 22559 & 1341 \\
\hline Nov & 2452 & 956 & 46913 & 3091 & 926 & 3367 & 874 & 3256 & 846 \\
\hline Dec & 1498 & 1128 & 30990 & 2052 & 1122 & 2351 & 1092 & 2132 & 1068 \\
\hline Total & 297017 & 39113 & 5454052 & 362816 & 35364 & 388520 & 28550 & 381820 & 25977 \\
\hline
\end{tabular}

\section{d. Comparison with the existing TVC-MED plant at Trapani}

From the above analysis it is clear how during winter time there is not enough solar resource to power a CSP system at full load, independently of the thermal storage and solar multiple used (within reasonable ranges). Because of this, the CSP plant could not be simulated to run with the same operational base-load profile of the existing TVC-MED plant at Trapani. Otherwise natural gas boilers would need to be used as backup whenever solar thermal energy would not be available, making this cogeneration system highly inefficient under these conditions.

However, it is worth noting that water and electricity consumption in Trapani, and in Sicily in general show a seasonal profile, with high demand in the summer time and low demand in the winter. Moreover, in this region, large scale water storage is possible as rain water is typically collected in winter time and stored in artificial lakes, acting as large open reservoirs.

Having these factors into account, for the location of Trapani producing water with a desalination plant does not strictly require a constant output throughout the year. In summer time the peak demand could be met by a CSP+MED/SWCC system, while in winter time lakes and reservoirs could provide the fresh water (gathered from rain fall or storage of excess production from the MED plant during summer time). Such an electrical and water production profile is actually something that current utility electrical and water operators would favor for this Italian region in order to face the large seasonal variability of water availability/demand.

Finally, in order to obtain the same water production as the real TVC-MED plant installed at Trapani (and assuming a capacity factor of 90\%), the above-mentioned CSP+MED/SWCC system 
would need to be oversized, requiring an installed capacity of $243 \mathrm{MW}_{\mathrm{e}}$ gross and an MED plant capable of producing $\sim 80000 \mathrm{~m}^{3} /$ day at design (instead of $110 \mathrm{MW}_{\mathrm{e}}$ gross and $36000 \mathrm{~m}^{3} /$ day). With this oversized CSP+MED/SWCC system, the water production curve would have the same profile than in figure 3 (with water and electricity production peaking during summer time), but the production curve would be oversized.

\section{Conclusions}

This paper presents a new model to simulate a CSP plant working in cogeneration with a MED Parallel-feed plant, as an add-on to the SAM code from NREL that simulates the operation of CSP plants. The MED model itself considers steady-state conditions and it is capable of simulating the operation of a MED plant with or without a TVC. This model was validated against data from a real industrial (stand-alone) TVC-MED plant that operates in the West of Sicily, Italy, in the vicinity of the city of Trapani. The main inputs into the MED model consist on the number of effects, temperatures to be used inside the evaporators, heat load available and seawater characteristics. The main outputs are the flow rates and output salinities. The results show that the outputs are within a $10 \%$ margin of error when compared with real data (for nominal conditions), being slightly over estimated. This deviation of the results is in line with the deviation given by SAM for the CSP plant performance.

The case study presented in this work compares the operation a CSP plant coupled with a SWCC in cogeneration with a low temperature MED parallel-feed plant. The MED plant was undersized regarding the nominal output of the CSP plant by $60 \%$ to allow the MED plant to operate more often under nominal conditions, being the variability of the CSP output absorbed by an extra condenser using seawater (the SWCC). The CSP+MED/SWCC plants were dimensioned so that the water output from the MED plant would be similar to the TVC-MED plant operating in Trapani. Three other cooling options for the CSP plant were analyzed in this work, namely: evaporative wet cooling (using saltwater), dry cooling and SWCC only. The CSP+MED/SWCC simulation considered as reference scenario had $110 \mathrm{MW}_{\mathrm{e}}$ gross installed capacity, with an estimated production per year of $\sim 297 \mathrm{GWh}_{\mathrm{e}}$ and $\sim 5.4$ million $\mathrm{m}^{3}$ of distillate. In this scenario the CSP plant obtains a yearly capacity factor of $34.2 \%$ and the MED plant $41.4 \%$ (the MED performs better as it was undersized with respect to the CSP plant nominal output). From all the mentioned cooling options, the CSP+MED/SWCC configuration had the worst performance (when analyzing only the net electrical output) producing in average throughout the year $\sim 22 \%$ less electricity than dry cooling, $\sim 29 \%$ less than SWCC and $\sim 31 \%$ less than wet cooling. On the other side, the integrated $\mathrm{CSP}+\mathrm{MED} / \mathrm{SWCC}$ allows the production of $\sim 5.4$ million $\mathrm{m}^{3}$ of fresh water, which can potentially compensate the reduction in power generation, especially in severely water-stressed regions, which are typically suitable places for the operation of a CSP plant.

In order to obtain a similar water production with a CSP+MED/SWCC system compared to the current TVC-MED plant at Trapani (and assuming a 90\% capacity factor for the existing plant), the CSP+MED/SWCC system would need to be roughly two times larger than the above-mentioned CSP+MED/SWCC system. For the location of Trapani this would probably be a good match with the local needs as both water and electricity demand peak during summer time. The water reservoirs in the region could be used only during winter time, complementing the MED production during the summer. These results show that CSP+MED may have the potential to be economically attractive in regions such as Sicily, as analyzed in the present work. 


\section{Acknowledgements}

The authors would like to acknowledge the EU and the seventh framework program for the financial support of this work under the STAGE-STE project with contract number 609837. This work was also supported by Fundação para a Ciência e Tecnologia (FCT), Portugal, through SFRH/BD/44969/2008 PhD grant, and by a research grant provided by the Luso American Development Foundation (FLAD).

The authors would like to thank also NREL's Thermal Systems Group for the collaboration given when integrating the MED model in SAM, Kinetic Therm and Körting Hannover AG for information on steam ejectors performances, and engineer Ricardo Encarnação Coelho from LNEG for the help with the weather file used in this work.

\section{Nomenclature}

\begin{tabular}{|c|c|c|}
\hline B & $\mathrm{kg} / \mathrm{s}$ & Mass flow of brine formed in each effect \\
\hline BPE & ${ }^{\circ} \mathrm{C}$ & Boiling point elevation \\
\hline CSP & - & Concentrated solar power \\
\hline $\mathrm{D}$ & $\mathrm{kg} / \mathrm{s}$ & Mass flow of distillate formed in each effect \\
\hline Delta_H_iph & $\mathrm{kJ} / \mathrm{kg}$ & $\begin{array}{l}\text { Difference between the specific enthalpy of the brine and feedwater } \\
\text { in each effect. }\end{array}$ \\
\hline Delta_Tf_iph & ${ }^{\circ} \mathrm{C}$ & Difference between $\mathrm{Tb}$ and $\mathrm{Tf}$ inside the effects \\
\hline Delta_Tv & ${ }^{\circ} \mathrm{C}$ & $\begin{array}{l}\text { Approximated value for the vapor temperature difference between } \\
\text { effects }\end{array}$ \\
\hline DeltaT_b_NEA & ${ }^{\circ} \mathrm{C}$ & $\begin{array}{l}\text { Non Equilibrium Allowance between the hotter brine (and not the } \\
\text { feedwater) entering each effect and the colder brine after flashing. }\end{array}$ \\
\hline DNI & $\mathrm{kWh} / \mathrm{m}^{2} / \mathrm{yr}$ & Direct Normal Irradiation \\
\hline e (subscript) & - & Electrical output \\
\hline E_Mm & $\mathrm{kg} / \mathrm{s}$ & $\begin{array}{l}\text { Motive steam used to power the non condensable gases steam } \\
\text { ejectors }\end{array}$ \\
\hline $\mathrm{F}$ & $\mathrm{kg} / \mathrm{s}$ & Mass flow of feedwater entering each effect \\
\hline FCT & - & Fundação para a Ciência e Tecnologia (FCT), Portugal \\
\hline FLAD & - & Luso American Development Foundation, Portugal \\
\hline Hb_b_flash_remain & $\mathrm{kJ} / \mathrm{kg}$ & $\begin{array}{l}\text { Specific enthalpy of the brine entering each effect after part of it has } \\
\text { flashed }\end{array}$ \\
\hline Hb_Tb_out & $\mathrm{kJ} / \mathrm{kg}$ & $\begin{array}{l}\text { Specific enthalpy of the brine leaving each effect (it is a mixture of } \\
\text { the brine from the previous effect plus the brine formed in the } \\
\text { current effect) }\end{array}$ \\
\hline $\mathrm{i}$ (subscript) & - & Subscript indicating the number of the effect \\
\hline LCOE & $\phi / \mathrm{kWh}$ & Levelized cost of electricity \\
\hline LHv & $\mathrm{kJ} / \mathrm{kg}$ & $\begin{array}{l}\text { Latent heat of the vapor at the saturated pressure at which each } \\
\text { effect operates }\end{array}$ \\
\hline
\end{tabular}




\begin{tabular}{|c|c|c|}
\hline LHv_b_flash & $\mathrm{kJ} / \mathrm{kg}$ & $\begin{array}{l}\text { Latent heat of the vapor formed by the brine flashing when entering } \\
\text { each effect }\end{array}$ \\
\hline LHv_evap & $\mathrm{kJ} / \mathrm{kg}$ & Latent heat of the vapor formed in each effect \\
\hline $\mathrm{Me}$ & $\mathrm{kg} / \mathrm{s}$ & $\begin{array}{l}\text { Total mass flow of saturated vapor entrained from the last effect of } \\
\text { the MED plant }\end{array}$ \\
\hline MED & - & Multi effect distillation \\
\hline $\mathrm{Mm}$ & $\mathrm{kg} / \mathrm{s}$ & $\begin{array}{l}\text { Total mass flow of motive steam powering the TVC of the MED } \\
\text { plant }\end{array}$ \\
\hline $\mathrm{n}$ & - & Number of Effects in the MED plant \\
\hline n_ph_NCG & - & $\begin{array}{l}\text { Number of the effect from where it is assumed that the external } \\
\text { preheating of the feedwater will be supported by NCG steam } \\
\text { extraction }\end{array}$ \\
\hline NCG & - & Non condensable Gases \\
\hline NEA & ${ }^{\circ} \mathrm{C}$ & Non Equilibrium Allowance \\
\hline NREL & - & National Renewable Energy Laboratory, US \\
\hline $\mathrm{P}$ & $\mathrm{Pa}$ & Saturated pressure at which each effect operates \\
\hline PR & $\begin{array}{l}\mathrm{Kg}_{\text {distillate }} \quad / \\
\mathrm{kg}_{\text {steam }}\end{array}$ & Performance ratio \\
\hline Q & $\mathrm{kW}$ & Thermal load in each effect \\
\hline $\begin{array}{l}\text { Q_brine_flash_superh } \\
\text { eat }\end{array}$ & $\mathrm{kW}$ & $\begin{array}{l}\text { Thermal load released when the vapor produced by brine flashing } \\
\text { passes from: superheated into saturated form. }\end{array}$ \\
\hline Q_eph & $\mathrm{kW}$ & Thermal load used to power the feedwater preheaters \\
\hline Qdistil_flash & $\mathrm{kW}$ & $\begin{array}{l}\text { Thermal load released by the distillate flashing inside the distillate } \\
\text { boxes }\end{array}$ \\
\hline Qv & $\mathrm{kW}$ & $\begin{array}{l}\text { Total sum of the heat load that can be delivered by the release of the } \\
\text { latent heat vapor formed inside each effect }\end{array}$ \\
\hline Qv_b_flash & $\mathrm{kW}$ & $\begin{array}{l}\text { Thermal Load released from the flashing occurring when brine } \\
\text { moves from effect to effect (temperature before and after flash are } \\
\text { due to the NEA). }\end{array}$ \\
\hline Qv_evap & $\mathrm{kW}$ & $\begin{array}{l}\text { Heat load of vapor formed inside each effect by evaporation process } \\
\text { alone }\end{array}$ \\
\hline $\begin{array}{l}\text { Qv_remain_after_preh } \\
\text { eating }\end{array}$ & $\mathrm{kW}$ & $\begin{array}{l}\text { Heat load of vapor formed inside each effect by evaporation process } \\
\text { only, that actually is used to power the next effect }\end{array}$ \\
\hline SAM & - & System advisor model \\
\hline SWCC & - & Once through seawater cooling circuit \\
\hline $\mathrm{Tb}$ & ${ }^{\circ} \mathrm{C}$ & Temperature of brine inside each effect \\
\hline Tb_b_flash & ${ }^{\circ} \mathrm{C}$ & $\begin{array}{l}\text { Final temperature of the brine after flashing inside the effect when } \\
\text { passing from effect } i-1 \text { to effect } i\end{array}$ \\
\hline $\mathrm{Tf}$ & ${ }^{\circ} \mathrm{C}$ & Temperature of feedwater entering each effect \\
\hline
\end{tabular}




\begin{tabular}{|c|c|c|}
\hline Ts_sat & ${ }^{\circ} \mathrm{C}$ & Temperature of saturated steam from the turbine \\
\hline $\mathrm{Tv}$ & ${ }^{\circ} \mathrm{C}$ & Saturated vapor temperature inside each effect \\
\hline TVC & - & Thermal vapor compressor \\
\hline $\mathrm{V}$ & $\mathrm{kg} / \mathrm{s}$ & Total mass of vapor produced inside the effect \\
\hline V_b_flash & $\mathrm{kg} / \mathrm{s}$ & $\begin{array}{l}\text { Mass flow of vapor produced inside each effect from the flashing } \\
\text { process occurring when the brine enters it. }\end{array}$ \\
\hline V_evap & $\mathrm{kg} / \mathrm{s}$ & $\begin{array}{l}\text { Mass flow of vapor produced by evaporation (not flashing) inside } \\
\text { the effect. }\end{array}$ \\
\hline $\mathrm{Xb}$ & $\mathrm{wt} \%$ & $\begin{array}{l}\text { Salinity concentration of the brine produced in each effect by } \\
\text { evaporation }\end{array}$ \\
\hline $\mathrm{Xf}$ & $\mathrm{wt} \%$ & Salinity concentration of the seawater (and feedwater) \\
\hline
\end{tabular}

\section{References}

[1] F. Trieb, et.al. Concentrating solar power for seawater desalination, Stuttgart: DLR; 2007.

[2] J. Blanco, et al. Thermodynamic characterization of combined parabolic-trough solar power and desalination plants in port safaga (Egypt), SolarPaces 2011.

[3] M. Wagner, P. Gilman. Technical manual for the SAM physical trough model. Technical report NREL/TP-55000-51825. USA: National Renewable Energy Laboratory; 2011.

[4] H. El-Dessouky, H. Ettouney. Fundamentals of salt water desalination. 1st ed. Amsterdam: Elsevier; 2002.

[5] N. Lior. Formulas for Calculating the Approach to Equilibrium in Open Channel Flash Evaporators for Saline Water, Desalination (60) 1986, pp. 223-249.

[6] A. Cipollina, G. Micale, L. Rizzuti. Investigation of flashing phenomena in MSF chambers, Desalination Vol.216, 2007, pp.183-195.

[7] A. Durante, et al. A large high-performance MED plant in Sicily, Desalination 105, 1996, 109114.

[8] A. Cipollina, G. Micale, L. Rizzuti. A critical assessment of desalination operations in Sicily, Desalination Vol. 182, 2005, pp. 1-12.

[9] A. Cipollina, A. Misseri, A. Galia, O. Scialdone, G. D’Alì Staiti, G. Micale. Integrated production of fresh water, sea salt and magnesium from sea water, Desalination and Water Treatment, 49, 2012, pp. 390-403.

[10] S. Casimiro, et al. Modeling multi effect distillation powered by CSP in TRNSYS. SolarPaces 2013, Energy Procedia, 49, 2014, pp. 2241-2250.

[11] Satel-light, The European Database of Daylight and Solar Radiation, Retrieved April 11, 2014 from http://www.satel-light.com/core.htm.

[12] J. Maulbetsch, M. DiFilippo. Performance, cost, and environmental effects of saltwater cooling towers. USA: California Energy Commission. PIER Energy-related environmental research program; 2008. 